The Journal of Animal \& Plant Sciences, 31(3): 2021, Page: 733-742

ISSN (print): 1018-7081; ISSN (online): 2309-8694

\title{
ANALYSIS OF ORGANOLEPTIC PARAMETERS AND HEAVY METALS IN ARTIFICIALLY RIPENED MANGO FRUITS IN PAKISTAN.
}

\author{
S. Abbas ${ }^{1}$, B. J. Azhar 1 , M. Irfan ${ }^{1}$, S. Ahmad ${ }^{2}$, I. Ahmed ${ }^{3}$, J. Hussain ${ }^{3}$ and S. N. Shakeel ${ }^{1,4^{*}}$ \\ ${ }^{1}$ Department of Biochemistry, Faculty of Biological Sciences, Quaid-i-Azam University, Islamabad, Pakistan. \\ ${ }^{2}$ Physics Division, Pakistan Institute of Nuclear Science \& Technology, Islamabad, Pakistan. \\ ${ }^{3}$ Experimental Physics Department, National Centre of Physics, Islamabad, Pakistan. \\ ${ }^{4}$ Department of Biological Sciences, Dartmouth College, Hanover, NH, USA. \\ *Corresponding Author's email: snq@qau.edu.pk
}

\begin{abstract}
Calcium carbide $\left(\mathrm{CaC}_{2}\right)$ is still commonly used as artificial fruit ripening agent for mangoes in many developing countries like Pakistan despite of the major concern of arsenic (As) and other metals contaminations. We used Particle Induced X-ray Emission (PIXE) for the detection of arsenic traces in commercially availableCaC $\mathrm{C}_{2}$ andartificially ripened mangoes (ARM). Presence of harmful arsenic residues in calcium carbide $\left(\mathrm{CaC}_{2}\right)$ treated fruits provided evidences that arsenic traces were transferred from calcium carbide $\left(\mathrm{CaC}_{2}\right)$ which is used for ripening. Mature green mangoes were treated with $\mathrm{CaC}_{2}$ in three different ways $\left(\mathrm{T}_{1-} \mathrm{T}_{3}\right)$ and were compared to fully ripened mangoes bought from local markets $\left(\mathrm{T}_{4}\right)$ and non-treated mangoes $\left(\mathrm{T}_{0}\right)$. Pulverized mango samples were irradiated by $3 \mathrm{MeV}$ collimated protons from $5 \mathrm{MV}$ tandem accelerator at National Institute of Physics, Pakistan and emitted X-ray spectrum was analyzed using GUPIXWIN to detect significant amount of As traces with differential presence of several other elements. Arsenic presence was further validated and endorsed in mango fruits using Graphite Furnace Atomic Absorption Spectrometry (GFAAS) and Inductivity Coupled Plasma Mass Spectrometry (ICP-MS). Absence of As traces in non-treated control mangoes has provided evidence of As contamination in artificially ripened mangoes is associated with $\mathrm{CaC}_{2}$ used for ripening. Arsenic residues in $\mathrm{CaC}_{2}$ treated mangoes can easily added up to already available arsenic exposure towards the limits shown for several cancerous diseases. Present study will not only provide a direct method of arsenic detection in fruits, but also suggest the need of strict implementations and improvements in the existing food safety rules and regulations to completely ban this carcinogenic chemical for its future applications.
\end{abstract}

Key words: PIXE; Arsenic; Hazardous; Calcium Carbide; Post harvest.

\section{INTRODUCTION}

Mango (Mangifera indica L.) is a climacteric fruit and commonly considered as "king of fruits" due to its excellent flavor, color, nutritious quality, attractive fragrance, and most importantly due to delicious taste. Pakistani mangoes rank good worldwide due to $\sim 139 \mathrm{kt}$ production and $\sim 7.6 \%$ share in the world market. In Pakistan almost 250 different mango varieties are found, while the most important commercial cultivars are Anwar Ratul, Dasehri, Langra, Sindhri, Chaunsa, Maldha and Fajri. Mango fruits usually mature in 100-150 days after flowering and then the fruit can possess its best flavor and aroma (depending upon the variety) if allowed to ripen on trees. In Pakistan, most of the mangoes are harvested at mature green stage and transferred to local markets, where ripening process is taken care by application of different chemicals before marketing. Mango fruit is extremely perishable to transport when fully ripened thus requires appropriate postharvest technologies for fruit ripening. Conventional fruit transportation methods and irregular storage are the main cause of more than $30-40 \%$ fruits lossin developing countries (Carrillo and Mariotti, 2000; Narayana et al., 1996; Shahbaz et al., 2009). Various artificial methods of fruit ripening have been observed mostly to meet consumers' demand and other economic factors. Different fruit postharvest practices such as hot water treatment, cold treatments, ethaphon, calcium chloride (Mahmood et al., 2013; Rahman et al., 2016; Gandhi et al., 2016) ethylene, and methyl jasmonate can be used. Ethylene, and methyl jasmonate are non-toxic ripening agents but relatively expensive.

Heavy metals are reported among the major contaminants of food supply and mainly considered as the most important form of environmental pollution (Zaidi et al., 2005; Khan et al., 2008). Heavy metals are hazardous contaminants in food and environment due to their non-biodegradable nature and continuous intake of heavy metals is of concern worldwide. According to the World Health Organization (WHO 1995), heavy metals must be controlled in food sources in order to assure public health safety. Excessive concentration of food heavy metals are found associated with the etiology of a 
number of diseases, especially cancer, cardiovascular, renal, neurological, and bone diseases (Chailapakul et al., 2008; Järup, 2003;Radwan and Salama, 2006;Beccaloni et al., 2013; Barone et al., 2015; Jackson and Punshon, 2015).

The popularity of $\mathrm{CaC}_{2}$ is based on its easy application,cost-effectiveness, rapid fruit ripening, help indirectly in fruit shelf life/transport, and mainly protects the texture, color and sweetness of the fruits for better marketing. On exposure to moisture, $\mathrm{CaC}_{2}$ produces acetylene gas $\left(\mathrm{C}_{2} \mathrm{H}_{2}\right)$, which enhances heat and fruit ripening similar to ethylene $\left(\mathrm{C}_{2} \mathrm{H}_{4}\right) . \mathrm{CaC}_{2}$ is produced in an electric arc furnace industrially by heating lime and coke mixture at $\sim 2000^{\circ} \mathrm{C}$. Commercially available $\mathrm{CaC}_{2}$ is not pure, as it always contains calcium arsenide $\left(\mathrm{Ca}_{3} \mathrm{As}_{2}\right)$ and calcium phosphide $\left(\mathrm{Ca}_{3} \mathrm{P}_{2}\right)$, which in presence of humidity changes to fat soluble arsine $\left(\mathrm{AsH}_{3}\right)$ andphosphene $\left(\mathrm{PH}_{3}\right)$ respectivelyfollowed by rapid diffusioninto the fruit skin and then deposits in the fruit pulp causing extremely hazardous effects on human health (Asif, 2012). Daily intakes of arsenic can cause diarrhea, irritation of digestive system, stomach cancer and liver failure. Free radicals from carbide play a major role in the ageing process as well as in the onset of cancers, heart disease, stroke, arthritis and perhaps different type of allergies (Essien et al., 2018).

Several analytical techniques have been recently used to determine the elemental composition of contaminated food samples, but usually due to complexity of sample preparation handling and additional steps can reduces the reliability of thepresence of particular element in the given samples. Advent and improvement of technologies such as, Proton Induced Xray Emission (PIXE), Graphite Furnace Atomic Absorption (coupling with cold vapor or hydride generation), Inductivity Coupled Plasma Optical Emission Spectrophotometer (ICP-OES), and Inductivity Coupled Plasma Mass Spectrometry (ICP-MS) made it easy to determine the quantities for any hazardous or beneficial elemental in the given samples including food (Haruyama and Saito, 1995; Flocchini et al., 1972; Zaidi et al., 2005; Radwan and Salama 2006; Naser et al. 2009; Jackson and Punshon 2015). Usually trace elements in food are in low concentrations, so we need really effective, robust, precise, accurate and sensitive method (Jackson and Punshon, 2015). Atomic and nuclear technologies has been very extensively utilized due adequate sensitivity to measure a wide range of elements in life sciences (Wang and Nastasi, 1995;Johansson and Campbell, 1988; Johansson. 1989;Naser et al., 2009; Bertrand et al., 2003) such as PIXE (Wang and Nastasi, 1995; Haruyama and Saito, 1995; da Silva et al. 2011; Stihi et al. 2008), and X-ray fluorescence (XRF) (Zaidi et al., 2005; Wang and Nastasi. 1995). PIXE can reliably, detect the presence of essential and toxic metals in parts per million (Johansson and Campbell, 1988; Flocchini et al., 1972; Pantelica et al., 2011; Kamal et al., 2007). Every method has its own pros and cons for different elements, therefore the use of more than one method can be helpful in term of increased the reliability and reduced the biasness in the analyzed results.

This study was aimed to check the presence of arsenictraces in the most favorite Pakistani mango variety "Langra" treated with $\mathrm{CaC}_{2}$. Weused a pragmatic approach for identification and quantification of inorganic As in mango samples using three different state of art technologies including, PIXE (at National Center of Physics, PK), GFAAS (at Pakistan Institute of Nuclear Science and Technology, PK) and ICP-MS (Dartmouth Trace Element Analysis Core Facility, Dartmouth College, USA). Fully ripened, ready to eat mangoes of the same variety were bought from the local markets and super markets of Islamabad, Pakistan. We included these mangoes in this comparative investigation to confirm the arsenic contamination in the mangoes.

\section{MATERIALS AND METHODS}

Fruit Sampling and Post-Harvest Treatments: Randomly selected un-ripened, green mangoes ( $\mathrm{cv}$ sindhri) of almost similar age were collected directly from the orchids located in district Multan(Province Punjab, Pakistan) and artificially ripened with $\mathrm{CaC}_{2}$. Fully ripened, ready to eat mangoes were bought from two different local markets including a small fruit shop and supper store (Islamabad, Pakistan). All of the fruits were divided into five different groupsto check the presence of $\mathrm{As}$ due to $\mathrm{CaC}_{2}$ treatment in three replicates as, Group-1 $\left(\mathrm{T}_{0}\right)$ : Control mango fruits were kept inside the papers (used newspapers) for 4-6 days in a corrugated wooden container (dimension 7" x 12" x 26") without any chemical treatment and this group will be used as control for comparisons. Group $2\left(\mathrm{~T}_{1}\right)$ : Mango fruits were treated with $\mathrm{CaC}_{2}$ similar to the method used in our markets by placing $\mathrm{CaC}_{2}$ in an envelope in the corner of wooden boxes containing fruits and kept at $27 \pm 4{ }^{\circ} \mathrm{C}$ for 4-6 days. While, Group-3 ( $\left.\mathrm{T}_{2}\right)$ : Mangoes were initially immersed in $5 \%$ solution of $\mathrm{CaC}_{2}$ for 10 minutesand then stored for 4-6 days in wooden box as described above.Group-4 $\left(\mathrm{T}_{3}\right): \mathrm{CaC}_{2}$ powder was directly applied onto fruit surface for $10 \mathrm{~min}$ and then fruits were stored for4-6 days in a wooden box like above. Group-5: $\mathrm{T}_{4}$ : Fully ripened, ready to eat mango fruits of the selected variety were bought from local fruit markets.

Organoleptic Parameters: We measured the fruit aroma, and flavor of all the treated and control fruit samples as described by Hedonic scale (Larmond 1987). Critical judgment on the given Performa by a panel of 20 experts (30-50 years old) onrandomly cutmangoes into 67 piecesfor color, aroma and flavor. Peel colour of 
mangoes included in $\mathrm{T}_{2}-\mathrm{T}_{4}$ was compared to control untreated mangoes $\left(\mathrm{T}_{0}\right)$.

Mango Sample Preparations: Fully ripened fruits were peeled off and then samples were cut into small pieces with the help of uncontaminated steel knife. The samples were dried in an oven at $60{ }^{\circ} \mathrm{C}$ for $48 \mathrm{hrs}$ to remove all moisture present in peel and pulp. Dried samples were finally ground to make homogeneous powder using pre cleaned mortar and pestle.

Approximately $0.6 \mathrm{~g}$ of powder sample was weighed carefully by electronic balance and pelletized using Laboratory Hydraulic Press (Carver USA; mode: 4350, LC; Serial No. 4160505). Hydraulic press of 24000 psi was used to make pellets of $2 \mathrm{~mm}$ thickness and 13 $\mathrm{mm}$ diameter. Two pellets were formed from each sample. The pellets were placed in desiccators to avoid moisture and any environmental contamination. The pellets were also put under lamp for some time before PIXE analysis to get rid of any moisture because vacuum problem is created in chamber during analysis.

Elemental Analysis of Mango Fruits and Instrumentation: We examined and analyzed the edible part, pulp of mango fruits using,

PIXE Analysis: Ground fruit samples were compressed manually using Laboratory Hydraulic Press (Carver, USA; Model: 4350.LC; Serial No. 4160505) under pressure of 22000 Pounds/10 Metric Tons to make 13 $\mathrm{mm}$ pallets. Fruit pallets were irradiated with proton beam of $3 \mathrm{MeV}$ using 5MV Pelletron Tandem Accelerator at Experimental Physics Laboratory, National Centre for Physics, Islamabad. The collimated beam of size approximately $2 \mathrm{~mm}$ size was used to irradiate the samples in vacuum chamber. During irradiation, the beam current was in the range of 10 to $20 \mathrm{nA}$. The X-rays emitted in this process were measured by SDD with high resolution (FWHM $160 \mathrm{eV}$ at $5.9 \mathrm{keV} \mathrm{Mn} \mathrm{K \alpha}$ energy). The detector was placed at an angle of 450 to incident beam. The advantage of $45^{\circ}$ orientation is the maximum characteristic X-rays collection and minimum background radiations. The distance between detector and target was $6 \mathrm{~cm}$. Mylar absorber of $100 \mu \mathrm{m}$ with no hole was used between target and detector to reduce low energy background. The vacuum inside the scattering chamber was 10-6 torr.

To check the accuracy of experimental result NIST Standard reference material apple leaves (SRM 1515) was used. For quantitative analysis of sample GUPIXWIN software package was used. GUPIXWIN software package is used to convert spectral data into elemental concentration. GUPIXWIN software analyzes the spectrum for elements and the data finally are transformed to Microsoft Excel format where final graphs are designed.
Different elements present in all samples of fruits were identified and estimated their concentration by using this software package. The concentration of each element in fruits were obtained by analysing the data using HED files and satisfying the fit requirements. Similar spectrum of SRM is obtained by applying same process. The different peaks of spectrum relate to different elements in the sample. The region under peak corresponds to the concentration of specific element in sample.

GFAAS: Arsenic (As) analysis was carried out by graphite furnace atomic absorption spectroscopy (GFAAS) using a Perkin Elmer 5100/HGA 600 instrument at Pakistan institute of Nuclear Sciences and Technology (PINSTECH). The method parameters were previously optimized by establishing ash and atomization curves for each metal. Wet digestion of all the ground mango samples was done with $\mathrm{HNO}_{3}(65 \%)$ followed by heating at $70^{\circ} \mathrm{C}$ for one hour. $\mathrm{HClO}_{4}(70 \%)$ was added after cooling at room temperature and prolonged heating at $240^{\circ} \mathrm{C}$ was done to remove all the white fumes (Fatima and Rahman, 2009). Finally, the clear solution was analyzed after required dilution. We used Hitachi model Z-2000 polarized Zeeman Atomic Absorption Spectrophotometer for this study using dual modes of atomization, graphite furnace AAS (GFAAS) and flame AAS (FAAS) as routinely used at PINSTECH, Islamabad, Pakistan. The elemental measurements were further validated using standard reference materials (SRM) analysis taken from National Institute of Standards \& Technology (NIST).

ICP-MS: Almost $100 \mathrm{mg}$ of dried mango powder from all the samples was used to digest by using $2 \mathrm{mls}$ of $\mathrm{HNO}_{3}$ and heated to $180^{\circ} \mathrm{C}$ for 20 minutes. Cooled samples were brought up to $15 \mathrm{ml}$ volume using distilled water. Digested mango samples were diluted 100 times with distilled water and analyzed using Agilent 7700x ICP-MS in "He mode analytes" withintegration times $~ 500 \mathrm{~ms}^{-1}$ sec at central facility of Dartmouth College, NH, USA. Data was analyzed and elemental concentrations were calculated as described (Jackson and Punshon, 2015).

Written Informed Consent was also taken from the participants for this manuscript.

Dietary Intake of Arsenic (DAsI): Daily intake of As in an average adult was calculated by elemental data obtained from different $\mathrm{CaC}_{2}$ treated as well as nontreated control mango groups. Dietary As intake (DAsI) was assessedas follow,

$\mathrm{DAsI}=\mathrm{C} \times \mathrm{Q}$

Where, $\mathrm{C}$ is the concentration of As in the selected mangogroup ( $\left.\mu \mathrm{g} \mathrm{g}^{-1}\right)$ and $\mathrm{Q}$, daily consumption of mangoes ( $\mathrm{g} \mathrm{kg}^{-1}$ of body weight) in 2-3 days (World Health Organization, 2009; EFSA, 2010). 
Validations and Statistical Analysis: All the elemental analysis was done in three replicates of all the pooled mango samples in different groups after treatment. For accuracy and reproducibility, certified reference materials were used for the instrumental calibrations. This study was conducted to evaluate the effect of $\mathrm{CaC}_{2}$ on organoleptic parameters and elemental profiling of mango fruit therefore One-way ANVOA with fixed effects was preferred to identify the statistically significant difference in among different studied groups. Tukey's HSD (honestly significant difference) test was employed for multiple comparison followed by Dunnett's test, Scheffé method and Bonferroni and Holm procedure. Different methods were employed to focus on biologically meaningful results which can be vital in a greater inspection of biologically interesting effects.

For Tukey's HSD, Scheffé method and Bonferroni and Holm procedure, an online calculator was used

(https://astatsa.com/OneWay_Anova_with_TukeyHSD/). Dunnett's test was employed by using MS Excel.

Then correlation analysis (using Pearson's correlation) was applied using MS Excel to check the correlation among heavy metals with elemental profile of artificial ripened mangoes.

\section{RESULTS AND DISCUSSION}

In this study calcium carbide $\left(\mathrm{CaC}_{2}\right)$ was investigated for its arsenic residues. For this purpose we purchased $\mathrm{CaC}_{2}$ from three different local suppliers. PIXE and GFAAS showed significantly high amount of arsenic traces ( $\sim 990-1153 \mathrm{ppm})$. Such a high amount of inorganic arsenic can contaminate the fruits when treated with $\mathrm{CaC}_{2}$ for the purpose of artificial ripening. Arsine (gas) released from contaminated $\mathrm{CaC}_{2}$ combines with air to form inorganic arsenic compounds, which have toxic and carcinogenic effects due to consumption of such fruits. Consumption of heavy metal contaminated fruits can cause heavy metal toxicity and cancer in Pakistan.

To investigate the presence of Astraces in artificially ripened mango fruits due to commonly used postharvest treatment of $\mathrm{CaC}_{2}$ in Pakistani local markets, we treated un-ripened green mangoes with $\mathrm{CaC}_{2}$ in different ways as shown in the Table-1. We also used a market mimicry treatment method used in our local markets (addition of $\mathrm{CaC}_{2}$ packets in mango containers and kept for 2-4 days (Group-2). Different treatment groups were compared for their elemental analysis with control (non-treated, Group-1) mango fruits and fully ripened, ready to eat mangoes bought from local markets (Group-4). The effects of $\mathrm{CaC}_{2}$ on organoleptic properties of mangoes were assessed. As expected the control mangoes showed delayed ripening with green and yellow non-homogenous patches even after 4-5 days (Table2).The fruit color change is usually result of unmasking of fruit pigments through chlorophyll degradation, anthosyanin synthesis and carotenoids accumulations, in either case of natural or artificial fruit ripening. Similarly, increased metabolism and hydrolysis, decreased fruit acidity, and sugars can bring sweetness(Islam et al., 2016). Application of artificial ripening agent can speed up the ripening mechanism when required. The mangoes of Group-2 were fully ripened in 2-3 days with homogeneous attractive yellow color and nice texture that no one can virtually distinguish from naturally ripened fruits. While, application of $\mathrm{CaC}_{2}$ in treatment Group-3 and 4 , where we treated green mangoes only for $10 \mathrm{~min}$ initially (Table-1),resulted in non-homogenous greenish yellow color due to short term acetylene gas production in the container which wasnot enough to fully ripe mango fruits but the process was initiated. Fruit ripening by using $\mathrm{CaC}_{2}$ does not required any technical training so local fruit venders use it in higher quantities to ripen immature fruit. Therefore, neither of our $5 \% \quad \mathrm{CaC}_{2}$ treatment nor direct $\mathrm{CaC}_{2}$ application for 10 min showed much effect on mango fruit ripening in our experimental conditions.

Fruit ripening is a biochemical process which involves a number of metabolic activities such as enhanced ethylene production and respiration, change in carbohydrates, synthesis of carotenoids, degradation of chlorophyll and conversion of starch into sugars. These activities lead to a series of physiological changes in color, taste, flavor, aroma and texture to consumer's acceptable level. All these factors combine to develop a complete sensory and edible profiles of a fruit (Lalel et al., 2003). Among the physiological properties, the skin color of the mango fruits is a vital characteristic for its marketing as it makes the commodity more attractive. Our data showed homogenous yellowcolor of mangoes of the Group-2 $\left(\mathrm{T}_{1}\right)$ like market fruits as expected due to almost same effect of $\mathrm{CaC}_{2}$. The appearance and smoothness of fruit skin is also very important acceding to consumers view point. Mangoes of Group-2 were perfectly ripened and attractive in comparisons to control group (shriveled and un-ripened patches on peel).

Anjum and Ali (2004) conducted a study to investigate the effects of different calcium salts (calcium chloride, calcium sulphate and calcium ammonium nitrate) on organoleptic parameters and they concluded that these salts delayed the ripening process of mangoes (cv. Kala Chaunsa) and positively influenced the skin and pulp colour but badly affected the aroma, flavour and taste of mangoes and hence resulted in bad/poor eating quality. Another similar study was conducted by Mehmud et al. (2015) and they used calcium carbide along with calcium chloride, calcium sulphate and calcium ammonium nitrate to investigate organoleptic parameters of Lokhna, Himsagor, Gopalvogh and Langra varieties of mangoes and they concluded that $\mathrm{CaC}_{2}$ hastened the ripening process and improved the texture, 
aroma and taste of mangoes. Padmini and Prabha (1997) reported that mangoes fruits treated with $\mathrm{CaC}_{2}$ attained attractive yellow colour, because of high carotenoids content, earlier than untreated control group. Our results corroborate with Padmini and Prabha (1997) and Mehmud et al. (2015).

We also observed effect of $\mathrm{CaC}_{2}$ and its toxicity by difference in color of dried ground powder of mango pulp and peel samples of all the treated groups with the control (non-treated) group of mangoes. Dried peel and pulp powder of mangoes included in control group retained their distinct orange-yellow color while toxic effects of $\mathrm{CaC}_{2}$ has turned dried peel and pulp powders of mangoes included in T1-T4 into dark brown or blackishbrown color (Fig-1 A \& B).We analyzed the elemental concentrations of only mango pulp due to, i) Pulp is the main edible part of the fruit, ii) Peel pallets were very brittle and not compact enough to proceed with PIXE analysis. Proton beam irradiated hydraulically pressed pallets of all the treatmentsand control fruit groups are given in Fig-1C.

Quantitative analysis of all essential as well as the trace elements of different groups of mango fruits were done with PIXE and concentration of elements in parts per million (ppm) including sulfur $(\mathrm{S})$, potassium $(\mathrm{K})$, calcium $(\mathrm{Ca})$, iron $(\mathrm{I})$, manganese $(\mathrm{Mn})$, nickel $(\mathrm{N})$, copper $(\mathrm{Cu})$, zinc $(\mathrm{Zn})$ and arsenic (As) were determined from spectrum obtained with $3 \mathrm{MeV}$ proton beam followed by analysis using GUPIXWIN software. Presence of peak for arsenic (10.543 keV) in PIXE spectra of all the $\mathrm{CaC} 2$ treated mango samples and absence of peak for arsenic in control samples are evidence of arsenic contaminations in $\mathrm{CaC}_{2}$ treated mangoes (representative spectra of all the groups are shown in the Fig-1D).For validation purpose, the elemental concentrations of Standard Reference Material (SRM) provided by NIST weremeasured at NCP (National Centre for Physics) Islamabad, Pakistan initially which were close to the certified values $(7-10 \%$ variations due to different experimental conditions). Our data showed negligible difference inthe elemental concentrations of all the major and minor elements in given treatment groups andcontrol group except the concentration of As (Table-3). Interestingly, no As traces were detected in the control (non-treated) mango pulp samples, while significantly high concentrations of As was found in fully ripened mangoes taken from market $\left(\mathrm{T}_{4}\right)$ and ourtreatment $\mathrm{T}_{2}$ (replica of market $\mathrm{CaC}_{2}$ treatment) as shown in Fig.2A.A small amount of arsenic residues were detected in mango fruits treated with $\mathrm{CaC}_{2}$ for $10 \mathrm{~min}$ (T2\& T3). Reason for less arsenic detection can be less availability of $\mathrm{CaC}_{2}$, or arsenic settles down in solution form and provides less contact with in sort time. Our results corroborate with Chandel et al. (2017).Absence of arsenic in control mangoes provide evidence that As contamination in the mango fruits is linked to $\mathrm{CaC}_{2}$. However, different concentrations of As have been found in different treatments of fruits with $\mathrm{CaC}_{2}$. The highest amount of As was observed in the group-2 mangoes followed by market samples thus confirmed the commercial use of $\mathrm{CaC}_{2}$ for fruit ripening (Fig 2A)for local use only, as $\mathrm{CaC}_{2}$ is strictly ban worldwide and cannot be used for export quality fruits due to regular monitoring and quality checks internationally.Therefore alternative methods for postharvest treatments are being used for export quality fruits to sell in global markets.

From correlation matrix it is revealed that arsenic in mangoes pulp has moderate negative correlation with phosphorus $\mathrm{P}\left(\mathrm{r}^{2}=-0.59\right)$ and potassium $\mathrm{K}\left(\mathrm{r}^{2}=-0.5\right)$ while it showed very strong negative correlation with calcium $\mathrm{Ca}\left(\mathrm{r}^{2}=-0.83\right)$

Data obtained from PIXE clearly revealed that arsenic residue present in $\mathrm{CaC}_{2}$ treated mangoes were only due to $\mathrm{CaC}_{2}$ treatment (Figure 3a). We validated PIXE results by GFAAS and ICP-MS.Both methodsalso confirmed the presence of As traces in different groups including market mangoes, though due to different levels of instrumental sensitivities, a direct comparisons of the relative quantifications of As detected in the samples by different methods was not possible (Fig 2). ICP-MS, the most sensitive technique available for such analysis (Jackson and Punshon, 2015) also confirmed the presence of As in all the treatment groups in comparisons to control samples (Fig 2B \& C).

Arsenic residues detected in artificially ripened fruits can disturb different body as well as metabolic functions and these arsenic traces can lead to various lethal diseases like cancer(Siddiqui and Dhua, 2010). Therefore, we also calculated daily minimum amount of As intake due to consumption of $\sim 200 \mathrm{mg}$ of $\mathrm{CaC}_{2}$ treated mangoes per day per body weight of $\sim 60 \mathrm{Kg}$ and our PIXE data showed As consumption $\sim 1-9.8 \mu \mathrm{g} / \mathrm{kg}$ body weight (bw) per day. Due to its popularity of this fruit and unavailability during off season in local markets, mango consumption increases many folds in Pakistan. Whereas the bench mark dose of $0.3-8 \mu \mathrm{g} / \mathrm{kg}$ body weight (bw) per day of As to cause $1 \%$ increased risk of cancer was recently published for adults and even less for kids and toddlers (Gundert-Remy et al., 2015). Now a days, major emphasis is on to reduce the arsenic exposure and to make long term measures to reduce the arsenic contaminations in food because of arsenic presence ubiquitously in soil and food chain is already at alarming levels. Recent studiescomprising 1200 samples of groundwater from Pakistan already showed detailed hazard with risk maps of elevated As contamination in groundwater with thresholds of 10-50 mg/liter and $\sim 50$ 60 million people are using that groundwater in Lahore and Hyderabad, Pakistan (Podgorski et al., 2017). Based on our calculations, the higher rate of mango consumption during season can accumulate dangerous 
levels of $\mathrm{As}$ in our bodies through $\mathrm{CaC}_{2}$ treated fruits and is linked to increased percentages of cancerous diseases in Pakistan.

We also examined $\mathrm{CaC}_{2}$ powder bought from local market which was used to ripen fruits (mangoes) for this study and commercial grade $\mathrm{CaC}_{2}$ used in the market by PIXE. Enormous amount of arsenic $(153 \mathrm{mg} / \mathrm{kg})$ and phosphorus $\left(155 \mathrm{mg} / \mathrm{kg}\right.$ ) was recorded in these $\mathrm{CaC}_{2}$ samples.

On daily consumption of such artificially ripened mangoes arsenic may damage different body organs and metabolic functions of the consumers which may lead to various lethal diseases like cancer. We calculated and compared the mean estimated daily intakes (MEDI) of elements detected by PIXE. The provisional tolerable daily intakes (PTDI) recommended by Joint $\mathrm{FAO} / \mathrm{WHO}$ Expert Committee on Food Additives are $1.5 \mathrm{mg} / \mathrm{kg}$ bw for $\mathrm{Cr}, 0.14 \mathrm{mg} /$ day $\mathrm{kg}$ bw for $\mathrm{Mn}, 0.7 \mathrm{mg} /$ day $\mathrm{kg}$ bw for Fe, $0.02 \mathrm{mg} /$ day $\mathrm{kg}$ bw for $\mathrm{Ni}, 0.4 \mathrm{mg} /$ day $\mathrm{kg}$ bw for $\mathrm{Cu}, 0.3 \mathrm{mg} /$ day $\mathrm{kg}$ bw for $\mathrm{Zn}$ and $0.0003 \mathrm{mg} /$ day $\mathrm{kg}$ bw for As. Our results revealed that arsenic detected in $\mathrm{CaC}_{2}$ ripened mangoes was much higher than the provisional tolerable daily intakes recommended by Joint FAO/WHO Expert Committee on Food Additive (Table 4).

Based onthis report and associated possible health hazards due to artificial fruit ripening agents, there is urgent need of extensive screening of varieties or fruits treated with $\mathrm{CaC}_{2}$. Some recent studies showed that artificial ripening of fruits results in decreased nutritional values of artificially ripened bananas and pineapples with special reference to vitamin $\mathrm{C}$, proteins and beta-carotene contents along with heavy metal contamination (Hakim et al., 2012; Mahmood et al., 2013; Zenebe et al., 2015; Islam et al., 2018; Maduwanti and Marapana, 2019).Regular consumption of such fruits on regular basis causes severe hazards to human health like diarrhea, skin allergy, central nervous system depression, liver and kidney disease, cancer, nausea, gastrointestinal irritation and vomiting (Hakim et al., 2012). Almost every country around the globe has food policies and regulations for artificial fruit ripening but implementation is lacking in developing countries like Pakistan, India, Bangladesh etc.(Islam et al., 2016).

Table-1. List of mango treatments with $\mathrm{CaC}_{2}$ in different groups.

\begin{tabular}{|c|c|c|}
\hline Samples & Ids & Mango Treatments \\
\hline Group-1 & $\mathrm{T}_{0}$ & Control non-treated mango samples were kept inside corrugated wooden container (dimension 7" x 12" x 26"). \\
\hline Grou & $\mathrm{T}_{1}$ & $\begin{array}{l}\text { Fruits were treated with } \mathrm{CaC}_{2} \text { to mimic the commercially used method by placing } \mathrm{CaC}_{2} \text { in an envelope in the } \\
\text { corner of wooden box. }\end{array}$ \\
\hline Group-3 & $\mathrm{T}_{2}$ & $\begin{array}{l}\text { Mangoes were initially immersed in } 5 \% \text { solution of } \mathrm{CaC}_{2} \text { for } 10 \text { minutes following storage for 4- } 6 \text { days in wooden } \\
\text { box. }\end{array}$ \\
\hline Gro & $\mathrm{T}_{3}$ & $\mathrm{CaC}_{2}$ powder was directly applied onto fruit surface for $10 \mathrm{~min}$ followed by $4-6$ days storage in a wooden box. \\
\hline Grou & $\mathrm{T}_{3}$ & $\begin{array}{l}\text { Fully ripened, ready to eat mango fruits of same selected variety were bought directly from local fruit shop and } \\
\text { supper market. }\end{array}$ \\
\hline
\end{tabular}

Table-2. Organoleptic characteristics of mango fruits.

\begin{tabular}{|c|c|c|c|c|c|}
\hline Parameter & $\begin{array}{l}\text { Group 1 } \\
\mathrm{T}_{0}\end{array}$ & $\begin{array}{l}\text { Group } 2 \\
T_{1}\end{array}$ & $\begin{array}{l}\text { Group } 3 \\
T_{2}\end{array}$ & $\begin{array}{l}\text { Group } 4 \\
T_{3}\end{array}$ & $\begin{array}{l}\text { Group } 5 \\
\mathrm{~T}_{4}\end{array}$ \\
\hline $\begin{array}{l}\text { Time required for } \\
\text { ripening }\end{array}$ & 5-6 days & 2 days & 3.5 day & 4 day & $\begin{array}{l}\text { Bought } \\
\text { ripened }\end{array}$ \\
\hline Color of the skin & $\begin{array}{l}\text { Greenish with } \\
\text { yellowish patches }\end{array}$ & $\begin{array}{l}\text { Uniform } \\
\text { color }\end{array}$ & $\begin{array}{l}\text { Greenish yellow } \\
\text { with dark patches }\end{array}$ & $\begin{array}{l}\text { Greenish yellow } \\
\text { with dark patches }\end{array}$ & $\begin{array}{l}\text { Uniform } \\
\text { color }\end{array}$ \\
\hline $\begin{array}{l}\text { Flavor, pulp color, } \\
\text { aroma }\end{array}$ & $\begin{array}{l}\text { Late ripened, soft } \\
\text { pulp and attractive }\end{array}$ & $\begin{array}{l}\text { Fully ripened, nice } \\
\text { pulp and very } \\
\text { attractive }\end{array}$ & $\begin{array}{l}\text { Same as control but } \\
\text { less attractive }\end{array}$ & $\begin{array}{l}\text { Same as control but } \\
\text { less attractive }\end{array}$ & $\begin{array}{l}\text { Fully ripened, nice } \\
\text { pulp and very } \\
\text { attractive }\end{array}$ \\
\hline Skin shriveling & $\begin{array}{l}\text { Little bit due to } \\
\text { delayed ripening }\end{array}$ & No & Too much shriveled & $\begin{array}{l}\text { Shriveled } \\
\text { widespread }\end{array}$ & No \\
\hline
\end{tabular}

Table 3: Concentrations of Different Elements (in ppm) in Mango Fruit Samples treated with Different Concentrations of $\mathrm{CaC}_{2}$ and Fruits from Market.Same letters indicate no significant difference . measured by One way ANOVA with post-hoc Tukey HSD test.

\begin{tabular}{llllll}
\hline PIXE Analysis & & \multicolumn{3}{c}{$\mathbf{C a C}_{\mathbf{2}}$ Treatments } & \\
\hline Elements & $\mathbf{T}_{\mathbf{0}}$ & $\mathbf{T}_{\mathbf{1}}$ & $\mathbf{T}_{\mathbf{2}}$ & $\mathbf{T}_{\mathbf{3}}$ & $\mathbf{T}_{\mathbf{4}}$ \\
Al & $8.525 \pm 1.73^{\mathrm{a}}$ & $7.175 \pm 0.07^{\mathrm{a}}$ & $7.975 \pm 0.05$ & $10.975 \pm 0.88 \mathrm{a}$ & $6.03 \pm 0.66^{\mathrm{a}}$ \\
$\mathbf{P}$ & $0.147 \pm 0.01^{\mathrm{a}}$ & $0.31 \pm 0.01^{\mathrm{b}}$ & $0.432 \pm 0.01^{\mathrm{c}}$ & $0.27 \pm 0.01^{\mathrm{b}}$ & $0.425 \pm 0.01^{\mathrm{c}}$ \\
$\mathbf{S}$ & $0.816 \pm 0.19^{\mathrm{a}}$ & $0.831 \pm 0.015^{\mathrm{a}}$ & $0.6465 \pm 0.06^{\mathrm{a}}$ & $0.3965 \pm 0.08^{\mathrm{a}}$ & $0.57 \pm 0.06^{\mathrm{a}}$ \\
\hline
\end{tabular}




\begin{tabular}{llllll}
\hline $\mathbf{C l}$ & & & & \\
$\mathbf{K}$ & $5.3225 \pm 2.16^{\mathrm{a}}$ & $7.3 \pm 0.28^{\mathrm{a}}$ & $10.125 \pm 0.08^{\mathrm{a}}$ & $5.85 \pm 0.212^{\mathrm{a}}$ & $6.76 \pm 3.3^{\mathrm{a}}$ \\
$\mathbf{C a}$ & $268.29 \pm 55.6^{\mathrm{a}}$ & $393.27 \pm 11.3^{\mathrm{a}}$ & $298.55 \pm 0.11^{\mathrm{a}}$ & $426.78 \pm 16.7^{\mathrm{a}}$ & $272.6 \pm 26.5^{\mathrm{a}}$ \\
$\mathbf{C r}$ & $123.6 \pm 45.57^{\mathrm{a}}$ & $125.1 \pm 11.3^{\mathrm{a}}$ & $79.375 \pm 1.92^{\mathrm{a}}$ & $121.975 \pm 14.2^{\mathrm{a}}$ & $85.9 \pm 11.8 \mathrm{a}$ \\
$\mathbf{M n}$ & $0.0861 \pm 0.02^{\mathrm{a}}$ & $0.254 \pm 0.008^{\mathrm{b}}$ & $0.16875 \pm 0.01^{\mathrm{a}}$ & $0.0738 \pm 0.003^{\mathrm{a}}$ & $0.075 \pm 0.02^{\mathrm{a}}$ \\
$\mathbf{F e}$ & $4.15 \pm 1.55^{\mathrm{a}}$ & $6.325 \pm 1.73^{\mathrm{a}}$ & $5.075 \pm 0.9^{\mathrm{a}}$ & $2.6250 \pm 0.318^{\mathrm{a}}$ & $4.45 \pm 0.07^{\mathrm{a}}$ \\
$\mathbf{N i}$ & $43.8 \pm 1.69^{\mathrm{a}}$ & $84.4 \pm 1.69^{\mathrm{a}}$ & $52.875 \pm 0.9^{\mathrm{a}}$ & $28.5 \pm 1.27^{\mathrm{a}}$ & $25.2 \pm 1.2^{\mathrm{a}}$ \\
$\mathbf{C u}$ & $0.542 \pm 0.4^{\mathrm{a}}$ & $0.969 \pm 0.09^{\mathrm{a}}$ & $0.56875 \pm 0.01^{\mathrm{a}}$ & $0.26575 \pm 0.03^{\mathrm{a}}$ & $0.221 \pm 0.07^{\mathrm{a}}$ \\
$\mathbf{Z n}$ & $0.6695 \pm 0.49^{\mathrm{a}}$ & $3.7 \pm 0.07^{\mathrm{b}}$ & $1.95 \pm 0.176^{\mathrm{a}}$ & $0.45175 \pm 0.06^{\mathrm{a}}$ & $1.45 \pm 0.83^{\mathrm{a}}$ \\
$\mathbf{A s}$ & $7.55 \pm 0.49^{\mathrm{a}}$ & $12.625 \pm 2.08^{\mathrm{a}}$ & $10.45 \pm 0.35^{\mathrm{a}}$ & $8 \pm 0.84^{\mathrm{a}}$ & $10.2 \pm 3.76^{\mathrm{a}}$ \\
\hline
\end{tabular}

Table 4.The mean estimated daily intake (MEDI) $(\mathrm{mg} / \mathrm{kg})$ of essential elements in $\mathrm{CaC}_{2}$ treated mangoes. The provisional tolerable daily intakes (PTDI) recommended by Joint FAO/WHO Expert Committee on Food Additives.

\begin{tabular}{|c|c|c|c|c|c|c|}
\hline \multicolumn{6}{|c|}{ Mean Estimated Daily Intakes(MEDI) } & \multirow{2}{*}{$\begin{array}{l}\text { Provisional Tolerable } \\
\text { Daily Intakes (PTDI) }\end{array}$} \\
\hline Elements & T1 & T2 & T3 & T4 & T5 & \\
\hline $\mathrm{Ca}$ & 0.25 & 0.3 & 0.356 & 0.348 & 0.273 & - \\
\hline $\mathrm{Cr}$ & 0.00062 & 0.0008 & 0.0005 & 0.002 & 0.002 & 1.5 \\
\hline Mn & 0.013 & 0.210 & 0.016 & 0.008 & 0.014 & 0.14 \\
\hline $\mathrm{Fe}$ & 0.146 & 0.281 & 0.176 & 0.095 & 0.084 & 0.7 \\
\hline $\mathbf{N i}$ & 0.001 & 0.003 & 0.001 & 0.0008 & 0.0007 & 0.02 \\
\hline $\mathbf{C u}$ & 0.0022 & 0.012 & 0.0065 & 0.0015 & 0.0048 & 0.4 \\
\hline $\mathbf{Z n}$ & 0.25 & 0.421 & 0.034 & 0.026 & 0.034 & 0.3 \\
\hline As & ND & 0.019 & 0.003 & 0.002 & 0.017 & 0.0003 \\
\hline
\end{tabular}

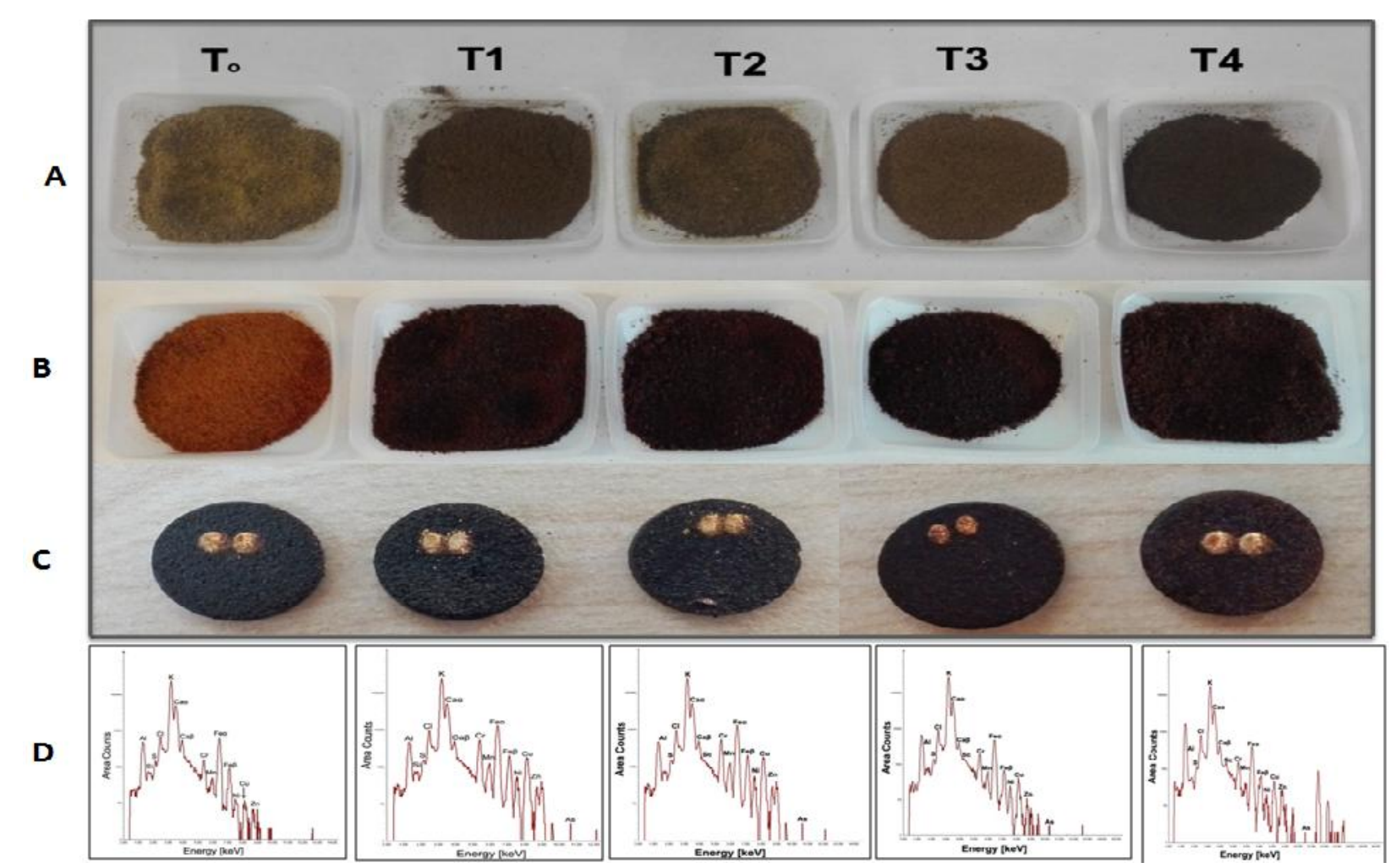

Figure 1: PIXE Analysis mango fruits with different concentrations of $\mathrm{CaC}_{2}$ treatments in comparisons to control (non treated fruits) and mango samples from markets. Fresh unripe mango fruitsamples were divided into five different groups and treated with $\mathrm{CaC}_{2}$ from $\mathrm{T}_{0}-\mathrm{T}_{4}$ as explained in Table-1. A) Ground mango fruit pulp samples demonstrating different groups of treatments. B) Ground mango fruit peel samples demonstrating different groups of treatments. C) Pallets of mango fruit pulp samples were irradiated using 3 Me V Protons for PIXE Analysis. D) PIXE spectrum of $\mathrm{CaC}_{2}$ treated groups of Mangoes. X-axis represents the energy of element and $\mathrm{Y}$-axis represents the Area counts of different metals. 


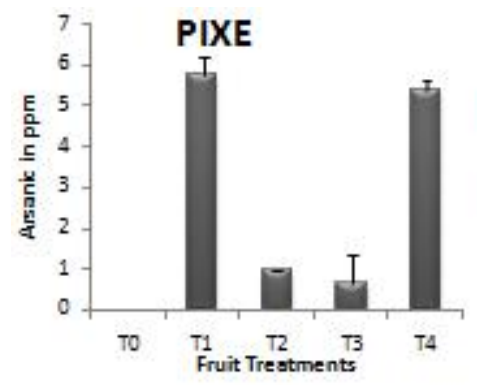

A

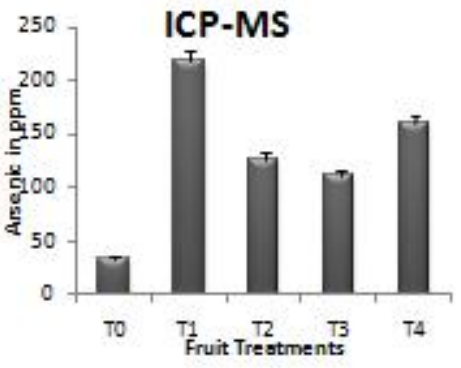

B

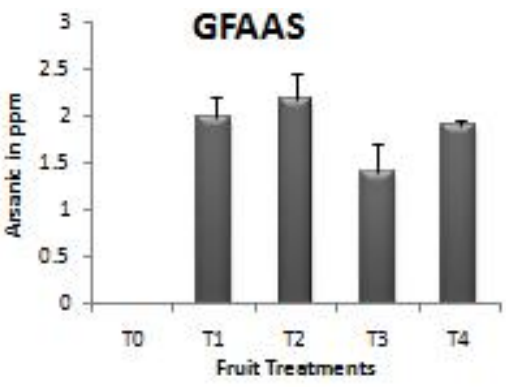

C

Figure 2. Analysis of mango fruits treated with different concentrations of $\mathrm{CaC}_{2}$ and market fruit samples with PIXE, ICP-MS and GFAAS. Fresh unripe mango fruitsamples were divided into five different groups and treated with $\mathrm{CaC}_{2}$ from $\mathrm{T}_{0}-\mathrm{T}_{4}$ as explained in Table-1. Presence of arsenic was analyzed in ground mango fruit pulp samples by three different independent methods, A) PIXE, B) ICP-MSand C) GFAAS.X-axis represents $\mathrm{CaC}_{2}$ treatments and $\mathrm{Y}$-axis represents presence of Arsenic in ppm.
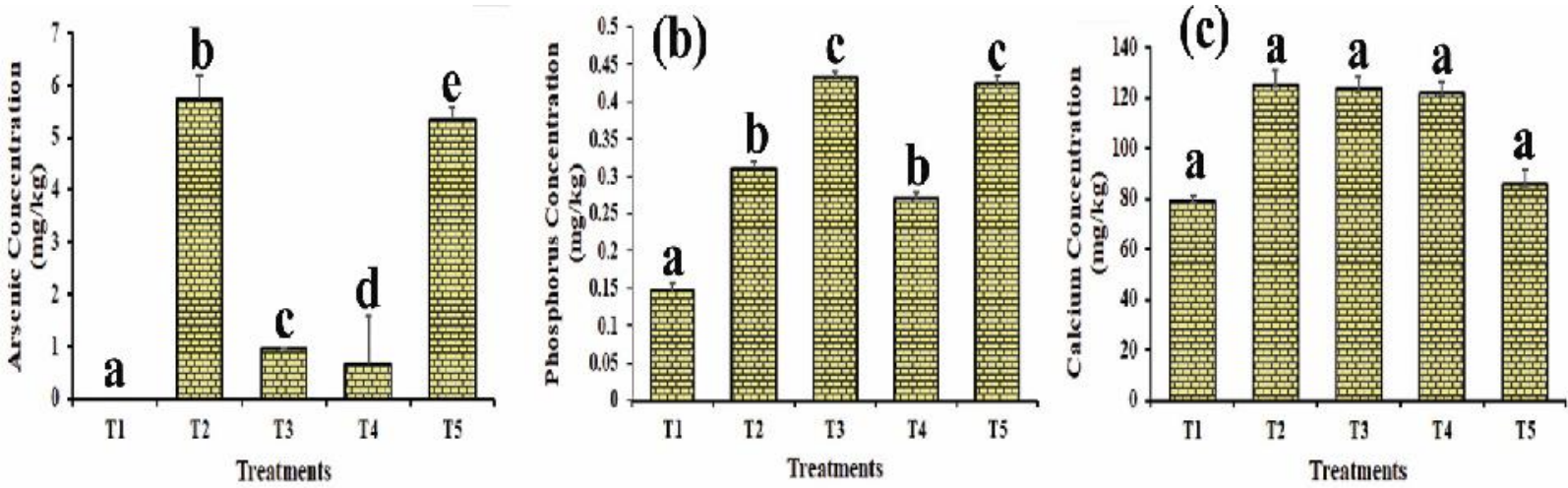

Figure 3:Effect of different treatments of calcium carbide on arsenic, phosphorus and calcium content of ripened mangoes fruit. Mature and green mango were collected from orchid and treated with different concentration of $\mathrm{CaC}_{2}$. Artificially ripened were ground to fine powder and arsenic was quantified (mg/kg) using PIXE. In this figure (a) represent arsenic concentration in mangoes(b) represent phosphorus concentration in mangoes and (c) represent calcium concentration in mangoes. $\mathrm{X}$-axis shows the group based on $\mathrm{CaC}_{2}$ treatment and $\mathrm{Y}$ axis shows the amount of arsenic $(\mathrm{mg} / \mathrm{kg})$ in artificially ripened mangoes. One way ANOVA with post-hoc Tukey HSD test was performed(https://astatsa.com/OneWay_Anova_with_TukeyHSD/). Same letters indicate no significant difference and the error bars represent the least squaremean $\pm \mathrm{SEM}, \mathrm{n}=3$.

Conclusions: This work provides the first direct evidence of the source of As contamination in artificially ripened mangoes throughthe use of calcium carbide, which is routinely used in Pakistan for fruit ripening especially for local consumption. Estimated daily intake arsenic levels are more than the WHO recommended guidelines and the higher rate of mango consumption during season can accumulate dangerous levels of As in our bodies through $\mathrm{CaC}_{2}$ treated fruits.Due to potential health risks, the use of calcium carbide is strongly discouragedworldwide and regulatory measures should be urgently taken to reduce the exposure of this carcinogenic element from the fruits like developed countries by using alternative post harvest technologies. Therefore, this hazardous chemical should be totally banned and further extensive studies are required to establish updated food safety/regulatory guidelines for Pakistani postharvest local technologies.This study will also help to educate the local fruit industry as well as the consumers to eliminate this cancer causing trace elements from our fruits.

Acknowledgements: This work was supported by research funding from Department of Biochemistry, Quaid-i-Azam University, Pakistan. Safdar Abbas (PIN 213-56801-2BM2115 (50023653)) and Beenish Jehan Azhar was funded Indigenous Scholarship by Higher Education Commission (HEC) Pakistan. We would like to acknowledge Dr. Jackson B and Dr.Punshon $\mathrm{T}$ for their help for ICP-MS as a portion of this work was conducted at the Dartmouth Trace Element Analysis Core facility, which is supported by a Superfund Research Program award to Dartmouth College, NIEHS P42 ES007373.We are grateful to Dr. Habib U.R, Syed A, Raza Zand Dr. Kashif N(Central analytical facility division, PINSTECH) for GFAAS analysis and technical staff of Department of Biochemistry, Quaid-i-Azam 
University, andNCP for their cooperation, assistance and support.

\section{REFERENCES}

Anjum, M. A and H. Ali (2004). Effect of various calcium salts on ripening of mango fruits. J. Res. Sci. 15(1): 45-52.

Asif, M., (2012). Physico-chemical properties and toxic effect of fruit-ripening agent calcium carbide. Ann. Trop. Med. Public Heal. 5:150-156.

Barone, G., A. Storelli, R. Garofalo, V.P. Busco,N.C. Quaglia, G. Centrone, and M. M. Storelli (2015). Assessment of mercury and cadmium via seafood consumption in Italy: estimated dietary intake (EWI) and target hazard quotient (THQ). Food Addit. Contam. Part A. Chem. Anal. Control. Expo. Risk Assess 32:12771286.

Beccaloni, E., F. Vanni, M. Beccaloni and M. Carere (2013). Concentrations of arsenic, cadmium, lead and zinc in homegrown vegetables and fruits: Estimated intake by population in an industrialized area of Sardinia, Italy. Microchem J. 10: 190-195.

Bertrand, M., G. Weber, and B. Schoefs (2003). Metal determination\&quantification in biological material using PIXE. Trends Anal Chem. 22:254-262.

Campbell, J. L., N. L. Boyd,N. Grassi, P. Bonnick, and J.A. Maxwell (2010). The Guelph PIXE software package IV. Nucl. Instr. Meth. Phys. Res. B Beam Interact. with Mater. Atoms. 268:3356-3363.

Carrillo, J.D., and T. Mariotti (2000). Strategic Ignorance as a Self-Disciplining Device. Rev Econ Stud. 67:529-544.

Chailapakul, O., S. Korsrisakul, W. Siangproh, K. Grudpan (2008). Fast and simultaneous detection of heavy metals using a simple and reliable microchip-electrochemistry route: An alternative approach to food analysis. Talanta. 74:683-689.

Chandal, R., P.C. Sharma and A. Gupta,(2017).Method for detection and removal of arsenic residues incalcium carbide ripened mangoes. J. Food Process. Preserv.42:e13420.

da Silva, D. G., M. M. S. Junior, L. O. B. Silva, L .A. Portugal, G. D. Matos and S.L.C. Ferreira (2011). Determination of cadmium in rice by electrothermal atomic absorption spectrometry using aluminum as permanent modifier. Anal. Methods. 3:2495.

EFSA, (2010). Scientific Opinion on Arsenic in Food. EFSA J. 7: 1351.
Essien E.B., B.M. Onyegeme-Okerenta and J.O. Onyema (2018). Calcium Carbide as an Artificial FruitRipening Agent and its Physiological Effects on Wistar Rats. Clin. Exp. Med. Sci. 6(1): 47-61.

Flocchini, R., P. Feeney, R. Sommerville and T. Cahill (1972). Sensitivity Versus Target Backings For Elemental Analysis By Alpha Excited X-Ray Emission. Nucl Instr Meth. 100:397-402.

Gandhi, S., M. Sharma and B. Bhatnagar (2016). Comparative Study on the Ripening Ability of Artificial Ripening Agent (Calcium Carbide) and Natural Ripening Agents. G.J.B.A.H.S. 5(2): 106-110.

Hakim, M.A., A.K. ObidulHuq, M.A. Alam,A. Khatib, B. K. Saha, K. M. Formuzul Haque, and I.S.M. Zaidul (2012). Role of health hazardous ethephone in nutritive values of selected pineapple, banana and tomato. J. Food Agri. Environ. 10:247-251.

Haruyama, Y., and M. Saito (1995). Trace Element Analysis in flour. Int. J. PIXE. 5: 79-84.

Islam, M.N., M. Mursalat, and M.S. Khan(2016). A review on the legislative aspect of artificial fruit ripening. AgricFood Secur. 5: 8.

Islam, M.N., M.Y. Imtiaz, S.S. Alam, F. Nowshad, S.A. Shadman and M.S. Khan (2018). Artificial ripening on banana (musa spp.) samples: analyzing ripening agents and chnge in nutritional parameters. Cogent food and agri. 4(1): 1477232.

Jackson, B., and T. Punshon (2015). Recent Advances in the Measurement of Arsenic, Cadmium, and Mercury in Rice and Other Foods. Curr. Environ. Heal. Reports. 2:15-24.

Järup, L.(2003). Hazards of heavy metal contamination. Br. Med. Bull. 68:167-182.

Johansson, S.A.E.(1989). PIXE: a novel technique for elemental analysis. Wiley, Chichester, West Sussex, UK.

Johansson, S.A.E., and J.L. Campbell (1988). PIXE: a novel technique for elemental analysis. John Wiley and Sons United Kingdom.

Kamal, F.M., N.A.F.M. Mohee,M.J. Abedin,A. Shariff,and A.H.M. Saadat (2007). Trace Element Analysis by PIXE in Soil Samples of Hazaribagh Tannery Area. J. Env. Sci. 5:31-36.

Khan, S., L. Aijun, S. Zhang, Q. Hu, and Y.G. Zhu (2008). Accumulation of polycyclic aromatic hydrocarbons and heavy metals in lettuce grown in the soils contaminated with long-term wastewater irrigation. J. Hazard. Mater. 152: 506-515.

Lalel, H., Z. Singh, and S.C. Tan (2003). Elevated levels of $\mathrm{CO} 2$ in controlled atmosphere storage affects shelf life, fruit quality and aroma volatiles of mango, in: Proceeding XXVI International 
Horticultural Congress: Issue and Advances In Postharvest Horticulture.

Larmond, E., (1987). Sensory evaluation can be objective. CRC Press Inc. Boca Raton, Florida

Mahmood, T., I. Saeed, H. Anwer, and I. Mahmood (2013). Comparative study to evaluate the effect of calcium carbide $\left(\mathrm{CaC}_{2}\right)$ as an artificial ripening agent on shelf life, physio-chemical properties, iron containment and quality of prunus persica. Batsch.Eur. Acad. Res. 1:685700.

Mahmud, S., A. Z. Shibly, M. M. Hossain, M. S. Islam, and R. Islam (2015).The effects of $\mathrm{CaC} 2$ and different calcium salt on mango fruits ripening in Bangladesh. J Pharmacogn Phytochem. 4(1): 210-215.

Maduwanthi, S. D. T., R. A. U. Marapana (2019). Induced ripening agents and their effect on fruit quality of banana. Int. J. Food Sci. https://doi.org/10.1155/2019/2520179

Maxwell, J. A., W. J. Teesdale, and J. L. Campbell (1995). The Guelph PIXE software package IV. Nucl. Instr. Meth. Phys. Res. B. 95:407-421.

Narayana, C., R. Pal, and S. Roy (1996). Effect of prestorage treatments and temperature regimes on shelf-life and respiratory behaviour of ripe Baneshan mango. J. Food. Sci. Technol. 33:7982.

Naser, H. M., N. Shi, N. Mahmud, M. Rashid, and K. Hossain (2009). Lead, cadmium and nickel contents of vegetables grown in industrially polluted and non-polluted areas of Bangladesh. Bangladesh J. Agri. Res. 34:545-554.

Padmini, S and T.N. Prabha (1997). Biochemical changes during acetylene-induced ripening in mangoes (var. Alphonso). Tropical Agriculture 74(4): 265-271.

Pantelica, A., A. Ene, M. Gugiu, C. Ciortea, and O. Constantinescu (2011). Pixe Analysis of Some Vegetable Species. Rom. Rep. Phys. 63: 9971008.

Podgorski, J. E., S. A. M. A. S. Eqanim, T. Khanam, R. Ullah, H. Shen, and M. Berg (2017). Extensive arsenic contamination in high-pH unconfined aquifers in the Indus Valley. Sci. Adv. 3:e1700935.

Radwan, M.A., and A.K. Salama (2006). Market basket survey for some heavy metals in Egyptian fruits and vegetables. Food. Chem. Toxicol. 44:12731278 .
Rahman, M.U., M. Sajid,A. Rab,S. Ali, M.O. Shahid,A. Alam,M. Israr,and I. Ahmad,(2016). Impact of calcium chloride concentrations and storage duration on quality attributes of peach (Prunuspersica). Russ. Agric. Sci. 42:130-136.

Shahbaz, M., Z. Iqbal, A. Saleem, and M. A. Anjum (2009). Association of lasiodiplodia theobromae with (Mangifera Indica L.). Pak J. Bot. 41:359368.

Siddiqui, M.W., and R. S. Dhua(2010). Eating artificially ripened fruits is harmful. Curr. Sci. 99:16641668.

Solls, C., A. Mireles,E. Andrade,and H. Zolezzi-Ruiz (2007). Environmental applications of PIXE at the Institute of Physics, UNAM. Rev. Mex. Fis. 53:33-37.

Stihi, C., I.V. Popescu, A. Gheboianu, M.A. Frontasyeva, A. Ene, G. Dima,O. Bute,V.A.L. Erica,G.H. Cimpoca, V. Stihi,C.D. Oros,S. Dinu, and M. Voicu (2008). Mineral Content of Native Vegetables Obtained By Energy Dispersive XRay Fluorescence Spectrometry. J.Sci. Arts. 9:332-335.

Tsukahara, T., T. Ezaki, J. Moriguchi,K. Furuki,S. Shimbo,N. Matsuda-Inoguchi,and M. Ikeda (2003). Rice as the most influential source of cadmium intake among general Japanese population. Sci. Total Environ. 305: 41-51.

Wallianos, A., P. Arndt, M. Maetz, T. Schneider, and K.Traxel (1997). Accurate quantification resulting from precise beam monitoring and calibration. Nucl. Instr. Meth. Phys. Res. 130:144-148.

Wang, Y. and M. Nastasi (1995) Handbook of Modern Ion Beam Materials Analysis. Materials Research Society, Pittsburgh, PA,.

[WHO] World Health Organization., 2009. Technical Report Seriesn. 959-Evaluation of certain contaminants in foods. Seventy-Second report of Joint FAO/WHO.

[WHO] World Health Organization., 2009. Inorganic lead. Geneva, World Health Organization, International Programme on Chemical Safety (Environmental Health Criteria 165

Zaidi, M.I., A, Asrar, A. Mansoor, and M.A. Farooqui (2005). The Heavy Metal Concentration along Roadside Trees of Quetta and its Effects on Public Health. J. Appl. Sci. 5: 708-711.

Zenebe, W.A., M.A. Ali, B.Y. Derbew and A.W. Tarekegn (2015). Effect of traditional kerosene smoking and ethrel on ripening, shelf life and qulity of cbendish banana (muss spp.). Afr. J. Agri. Res. 10(50): 4570-4583. 